\title{
Study on the Architectural Arts and Characteristics of Taihao Ling Temple in Huaiyang
}

\author{
Fuyan $\mathrm{Yu}$ \\ School of Art and Design \\ Huanghe Science and Technology College \\ Zhengzhou, Henan, China
}

\begin{abstract}
Taihao Ling Temple is a holy place for Chinese nation to worship ancestors. Its unique architectural style and great and profound culture connotation as well as rich folk characteristics make people feel amazing. On the basis of on-thespot investigation and literature research, the author tries to discuss and study historical culture, spatial arrangement and architectural features of ancient complex in Taihao Ling Temple.
\end{abstract}

Keywords-Taihao Ling Temple; historical culture; architectural features

\section{INTRODUCTION}

Taihao Ling Temple, also named temple of ancestors, is the final resting place for Father $\mathrm{Fu} \mathrm{Xi}$. Father $\mathrm{Fu} \mathrm{Xi}$ is the ancient emperor of Legendary Period in Ancient China. As the oldest emperor, he is the first of the Three Sovereigns and Five Emperors and is well known as the "father" of the Chinese nation.

Taihao Ling Temple lies in the north of the Cai river, 1.5 kilometers from Huaiyang county, Henan province. It covers $875 m u$ and it is one of the eighteen famous temples. Taihao Ling Temple was built in the Spring and Autumn Period. According to the local records, ancestral temple was built in Han and previous dynasties while the temple was not built until the Song dynasty. The existing wooden architecture was built in the 13th year of Zheng Tong in Ming dynasty (AD 1448) and had been repaired in Ming and Qing dynasties for many times. Because Taihao Ling Temple is the temple for humane primogenitor of the Chinese nation, it was also called "the first temple under heaven". Combining tomb and temple together, its big scale and majestic architecture make people sing for praises. Visiting Taihao Ling Temple by following the marks of "father" is of great significance undoubtedly to the study of ancient Chinese architecture and profound culture.

\section{UNIQUE HISTORICAL AND CULTURAL BACKGROUND AND GEOGRAPHY ENVIRONMENT}

\section{A. Profound History and Deep Connotation of Fu Xi}

When it comes to common ancestors of the Chinese nation, every people says he is the descendent of Yan and Huang emperor proudly. Actually, when tracing the source, we can find the common ancestor of the Chinese nation that earlier than Yan and Huang emperor is $\mathrm{Fu} \mathrm{Xi}$. With his own intelligence and boundless creativity, he contributed a lot in the transaction from matriarchal society to patriarchal society under evolution from brutalization to civilization. His contribution was such that people called him "Tai Hao".

$\mathrm{Fu} \mathrm{Xi}$ 's contribution to human was such great that descendants worshiped and memorized him. There were many Persons of rank of dynasties who came to worship him. Historical, natural and national factors covered many original scientific factors. Contents of Fu Xi culture contain widely, such as astronomy, geography, philosophy, religion, manufacture of production tools and local folk customs. They were all dated back to $\mathrm{Fu} \mathrm{Xi}$ culture. Therefore, $\mathrm{Fu} \mathrm{Xi}$ culture is the root culture of the Chinese nation.

\section{B. Advantaged Geography Environment of Taihao Ling Temple}

The Commentary of Zuo in the 17th Year of the Emperor Zhao Period said, Chen, is the space of Tai Hao.

The General History of China · About Tai Hao Fu Xi said, the emperor was dead ( having been an emperor for 115 years) and was buried in Chen. Then Shen Nong took his place and became the emperor.

Chen (county), located in Huaiyang county, Henan province. It was called Wanqiu or Chenzhou in ancient times. According to historical records and the intact temple, we can confirm the exact place of Taihao Ling Temple. There were countless letters, member of the Kings and princes in the ancient times coming here to gathering, which left a large number of ancient poems. Descendants of Fu Xi built splendid ancient culture of the Chinese nation, making it a bright light in the history. With a long history, Huaiyang has a unique cultural background and cultural environment. Brightly rippling water in the Long Lake and rich folk culture add primitive simplicity and magnificence to Taihao Ling Temple.

\section{Temple and Culture}

Liang Sicheng, a famous architect in China, said in his paper great tradition and heritage of China that, "every culture in history has its own architecture and the architecture Thrives and decays along with that of the culture. Among the existing cultures in world, besides the culture of India, which came into being at about the same time with that of the Chinese nation, the Chinese culture was the oldest and longest. So was the 
architecture of China. In the history, the other cultures, such as the cultures of Ancient Egypt and Babylon, as well as later Persia, had developed flourishingly for more than four hundred years and formed wholly". These words expressed the relationship between architecture and culture incisively.

Taihao Ling Temple is located in Henan province-a fertile place and one of the homes of Chinese nation. As is known to all, the architectural culture in Henan is profound and the number of the existing ancient architectures ranks among the top nationwide. With unique structure, beautiful art shape and plentiful decoration, the Taihao Ling Temple can be said a piece of treasure of the ancient Chinese culture and art in the architecture history of China, which means a lot in researching the ancient Chinese culture and art.

\section{A Simple ANALysis ABOUT the ANCIENT COMPLEX ARCHITECTURE IN TAIHAO LING TEMPLE}

The Taihao Ling Temple was built based on ancient Fu Xi gossip of mathematical sciences and faced south. The hall was tall and rugged, resplendent and magnificent among green pines and verdant cypresses. The length of the Taihao Ling Temple from south to north is 750 meters. The temple was made up of three imperial cities namely the outer city, the inner city and the Forbidden City. It has three temples, two buildings, two corridors, two lanes, a platform, an altar, a pavilion, a shrine, a hall, a park, seven abbeys and sixteen doors. The complex is mainly on the vertical axis, magnificent and reasonably arranged. From south to north we can see Wuchao Gate, Yudai Bridge, Daoyi Gate, Xiantian Gate, Taiji Gate, bell tower and drum tower, Tongtian Hall, Xianren Hall, Taishi Gate, Gossip Platform, Lingyuan Gate, Taihao Ling Temple and Alpine Yarrow Park. Opening the south and north doors step by step, we can directly see the big temple in the Forbidden City. The scene was quiet and capacious, making visitors thrilled, so it was called "ten doors matching well".

\section{A. Spatial Arrangement of the Ancient Complex Architecture in Taihao Ling Temple}

The western ancient architecture art pays attention to express majesty and magnificence of individuality, while that of China values broadness and pageantry of the group. Ancient China rules the country according to Confucianism because it is not only a kind of thought but also a behavior rule. It restricts both the social ethics and daily behaviors of people. Out of respect for the Confucian, the building group is exactly axisymmetric with a solemn atmosphere.

Spatial arrangement of the ancient complex architecture in Taihao Ling Temple is mainly displayed in the following three aspects:

1) Emphasis on Central Axis and Symmetric Layout: We can see the spatial arrangement of Taihao Ling Temple obviously from its aerial view. The complex is mainly on the vertical axis. From Wuchao Gate to the temple, there are ten door s and nine yards, making the temple the meteorological solemn, the occult and broad. Going north along the main Lord road from Wuchao Gate, the whole trip was a vertical line. By Penetration of a few large and small courtyards as well as the changes and transformation of space, we gradually reached the highest level of construction - Tongtian Hall, which prominently embodies the supreme status of the temple. Architectures on the axis and their affiliated parts are symmetric strictly and spread to both sides, forming the secondary axis, whereas buildings on the secondary axis such as the 4th abbey in west, the third abbey in east and the fire god platform, are roughly symmetrical or changed flexibly. Groups of architectures concatenate in the same axis while the north-south axis and the east - west axis intervein together, making the primary and secondary architectures different from each other clearly and the whole complex change in unity.

2) Flexible Application and Spatial Change of the Nine Yards: Another feature of ancient Chinese architecture layout is that courtyards are composed by single buildings and organized into a unit, then form various space group, every courtyard changes and contrasts in space and scale, producing different atmosphere. Taihao Ling Temple was called "ten doors matching well" and the nine yards are magnificent and majestic, which reflects their reasonable and flexible application. From Wuchao Gate to Tongtian Hall, there are three doors, one bridge and four closed space in Taihao Ling Temple. Its space is large at the beginning, then small and then large again. Entering Wuchao Gate, we can find the space is large with an open vision. Crossing the Yudai Bridge slowly, we can get to Daoyi Gate, we will find the space here is a little small. While appreciating the green pines and verdant cypresses along the trip, we can arrive at Xiantian Gate, we will find that vertical visual space is even smaller; behind Taiji Gate, there is a long and deep space. When feeling the space is open and clear, we reach the central yard of Taihao Ling Temple and the Tongtian Gate faces us directly. The comparison of space caters to the need of mental change and makes people in the central hall feel its mysterious feature dearly.

3) Architectural Layout Embodying Theory of Gossip: Gossip, is anciently called "a sealed book with no words" and the Book of Changes is called "the top of the books". Gossip is the great contribution of $\mathrm{Fu}$ xi to the Chinese nation and the center content of the Book of Changes, which composes the main frame of the Chinese culture. In the central yard of Taihao Ling Temple, Taiji Gate, Liangyi Gate, Sixiang Gate, Sancai Gate, Wuxing Gate, Yangguan Gate, Fucha Gate and Xantian Gate and so on form a stereo gossip picture. Designers use gates as the basis, and embody spirit by gates, meaning obtaining the spirit by gates. As a holy place to sacrifice ancestors, the gossip shows the spirits and soul of Chinese nation in solemn atmosphere.

\section{B. Features of Main Architectures in Taihao Ling Temple}

Taihao Ling Temple faces south and the existing wooden buildings are relics for the Ming and Qing dynasties. The "ten doors" in order are Wuchao Gate, Daoyi Gate, Xiantian Gate, Taiji Gate and so on, with main architectures Tongtian Hall, 
Xianren Hall, and the temple together lie in the central axis, forming a great ancient complex.

1) Wuchao Gate: Wuchao Gate is one of the main architectures in Taihao Ling Temple. It was built in Ming dynasty. The total gate is 10.35 meters high and with a single eave. The width of the gate is about 5.4 meters and the length is about the length of six columns with grey bricks and blue tiles, carved beams and painted rafters and red gate gold nail. Before the gate is a platform, and before the platform are three five-steps carved with elephant eyes. The ground is decorated with grey bricks, around bricks are stress stones and inside the wall are eight columns. In front of the gate, there are two opening wall like the Chinese character “八” respectively lying east and west. On the wall is the colorful invisible taiji diagram and pictures like the dragon body, Kylin, the Eight Immortals and peaches with distinctive national features. The ridge of grey pantile is fold, and the boundary of the eave is decorated with tiles of dragon design and water flows down from the channels painted with chrysanthemum. Above the gate are the horizontal inscribed board of Taihao Ling Temple, Wuchao Gate and Kaitianliji. On both sides of the Wuchao Gate about 24 meters apart, are relatively the east door and west door, their shapes are like steamed bread with plank door and humpbacked rafters.

2) Tongtian Hall: Behind the Taiji Gate, going north along the main Lord road, we can see the main architecture Tongtian Hall, which is commonly known as "big hall". It was built in the second year of emperor Zhengtong in Ming dynasty (AD1437). It is 15.7metrs high and covers more than 390 square meters, making it the biggest hall and rank first in the ancient complex. Tong, means discipline in explaining characters. Tongtian means commanding everything. On June 26, 1997, Zhu Rongji, the vice premier of China at the time, inspected the Taihao Ling Temple and authorized the repair report of the temple in October of that year. The government of Henan province acted as the main conductor and provided fund for the project. They added stone balustrade and carved "traces of $\mathrm{Fu} \mathrm{Xi"} \mathrm{on} \mathrm{indoor} \mathrm{green} \mathrm{stones.}$

Tongtian Hall is tall and majestic, spectacular and splendid, elegant and unsophisticated. The design of the hall is also unique. It lies in the central of the temple and its plane like a rectangle with rigorous structure. Its eave is built in the same style of Wuchao Gate and width and length are about 5.4 meters respectively. The ridge is carved with dragon and phoenix and covered with yellow glazed tiles. It is located on the vertical stylobate, which is composed of grey bricks and pressing stones. Before the platform are seven steps carved with elephant eyes. In the hall are sixteen peripheral columns and eighteen golden columns while plinth covers carefully carved pictures of lotus drum. The front of the hall is Shelf fan door and sill wall window. In east, west and north of the hall are brick walls. Below the ridge is the horizontal inscribed board with the name. In terms of the decoration, both sides are kinds of carved or splicing pictures with three-color bricks. South of the ridge are eight green dragons and north of that are eight golden phoenixes. The dragons and phoenixes symbolize tribes unity together, forming the bone of the Chinese nation.

3) Xianren Hall: It lies 36.2 meters far in the north of Tongtian Hall and rank only second to Tongtian Hall, so it is commonly called "the second hall". Xian, means Yang, and with Ren, together means parents while parents are the earth and heaven. Yin mixing with Yang produces everything in the world. The hall means remembering the roots and never forgetting the ancestors. It was built in the seventh year of emperor Jingtai in Ming dynasty (AD 1456).

Its plane likes a rectangle with many eaves covered by grey pantile. The ridge is carved with dragons and phoenixes, and it has a high corridor. The width and length are about 13 meters and 9 meters. It is 16.4 meters high based on a vertical stylobate. Before it are thirteen steps. There are 24 peripheral columns, 18 old peripheral columns and 8golden columns with mirror-liking plinth. The central and side rooms have sublattice doors while the old eave gate has corridor formed by brick wall and peripheral columns. Lifting beam frame, which is the most widely used in ancient Chinese timber frame. When the frame forms, the wall can be divided flexibly because it doesn't hold things. So there is an ancient saying: "the wall falls down while the house doesn't'.

\section{CONCLUSION}

Taihao Ling Temple is valuable not just because its significance and long history. To Chinese people, it is not a usual tomb, but a holy place making people admiring by its unique architecture style and rich human connotation. It is also a place for us to remember ancestors. A poem by Zhu Yanzhao in Qing dynasty said: "Before the hall is green pines and verdant cypresses, higher than the lake is the Taihao Ling Temple, ancestors of Chinese nations should be inherent thousands of years, drawing the history in a picture, the $\mathrm{Su}$ emperor gives little convenience to public, while thousands of loyal persons emerges, people celebrates happily in February every year, to sacrifice and pay respect to the ancestors", which expresses people's gratitude to $\mathrm{Fu} \mathrm{Xi}$ and the significance of Taihao Ling Temple. The structure and shape of Taihao Ling Temple reflect the features of architectures in Ming and Qing dynasties: simple in shape, plain in structure, steady and rigorous. The form of construction is succinct and has a strong symbolic meaning. Grey bricks and blue tiles, carved beams and painted rafters show the ancient unsophisticated style.

\section{REFERENCES}

[1] Yang Huancheng. China ancient architecture culture---In Henan[M].Beijing: Intellectual Property Publishing House Co,.Ltd, Jul, 2004.

[2] Zhang Fuhe. Papers collection on the history of architecture. Chapter 20[C]. Beijing: China machine Press, Apr, 2004.

[3] Li Naiqing. Taihao Ling Temple[M].Zhengzhou: ZZCCPH, May, 2005. 